\title{
Approach to Neonates and Young Infants with Fever without a Source Who Are at Risk for Severe Bacterial Infection
}

\author{
Susanna Esposito $\left(\mathbb{D},{ }^{1}\right.$ Victoria Elisa Rinaldi, ${ }^{1}$ Alberto Argentiero, ${ }^{1}$ Edoardo Farinelli, ${ }^{1}$ \\ Marta Cofini, ${ }^{1}$ Renato D'Alonzo, ${ }^{1}$ Antonella Mencacci $\mathbb{D}^{1},{ }^{2}$ and Nicola Principi ${ }^{3}$ \\ ${ }^{1}$ Pediatric Clinic, Department of Surgical and Biomedical Sciences, Università degli Studi di Perugia, Perugia, Italy \\ ${ }^{2}$ Microbiology Unit, Department of Medicine, Università degli Studi di Perugia, Perugia, Italy \\ ${ }^{3}$ Pediatrics, Università degli Studi di Milano, Milan, Italy
}

Correspondence should be addressed to Susanna Esposito; susanna.esposito@unimi.it

Received 29 May 2018; Revised 7 September 2018; Accepted 15 October 2018; Published 26 November 2018

Academic Editor: Mirella Giovarelli

Copyright (c) 2018 Susanna Esposito et al. This is an open access article distributed under the Creative Commons Attribution License, which permits unrestricted use, distribution, and reproduction in any medium, provided the original work is properly cited.

\begin{abstract}
Introduction. Among neonates and infants $<3$ months of age with fever without a source (FWS), $5 \%$ to $15 \%$ of cases are patients with fever caused by a serious bacterial infection (SBI). To favour the differentiation between low- and high-risk infants, several algorithms based on analytical and clinical parameters have been developed. The aim of this review is to describe the management of young infants with FWS and to discuss the impact of recent knowledge regarding FWS management on clinical practice. Materials and Methods. PubMed was used to search for all of the studies published over the last 35 years using the keywords: "fever without source" or "fever of unknown origin" or "meningitis" or "sepsis" or "urinary tract infection" and "neonate" or "newborn" or "infant $<90$ days of life" or "infant $<3$ months". Results and Discussion. The selection of neonates and young infants who are $<3$ months old with FWS who are at risk for SBI remains a problem without a definitive solution. The old Rochester criteria remain effective for identifying young infants between 29 and 60 days old who do not have severe bacterial infections (SBIs). However, the addition of laboratory tests such as C-reactive protein (CRP) and procalcitonin (PCT) can significantly improve the identification of children with SBI. The approach in evaluating neonates is significantly more complicated, as their risk of SBIs, including bacteremia and meningitis, remains relevant and none of the suggested approaches can reduce the risk of dramatic mistakes. In both groups, the best antibiotic must be carefully selected considering the clinical findings, the laboratory data, the changing epidemiology, and increasing antibiotic resistance of the most common infectious bacteria.
\end{abstract}

\section{Introduction}

Fever in neonates and infants $<3$ months of age is defined as a rectally obtained temperature $\geq 38^{\circ} \mathrm{C}[1-3]$. Fever is one of the most common reasons for emergency department and outpatient clinic visits by these patients; many of which have no diagnostically reliable signs and symptoms and receive a diagnosis of fever without a source (FWS) after initial clinical evaluation. These infants have been divided into two groups for many years. The first group includes patients suffering from mild, clinically irrelevant viral infections and the second group, accounting for $5 \%$ to $15 \%$ of cases, includes patients with fever caused by a serious bacterial infection
(SBI), i.e., invasive diseases (bacteremia/sepsis, meningitis) or severe, exceptionally invasive bacterial infections (pneumonia, urinary tract infection (UTI), and soft tissue and bone infections) [4]. Although difficult, the differentiation of neonates and young infants at risk of SBI from those without significant clinical problems is considered crucial. Early identification and treatment of patients with SBI is deemed essential to assuring favourable disease outcomes. Moreover, the selection of patients with low risks of SBI could permit the avoidance of unnecessary antibiotic treatments, hospitalization, and invasive laboratory tests.

To favour the differentiation between low- and high-risk infants, several algorithms based on analytical and clinical 
parameters have been developed [5-8]. However, while they were quite similar in some steps, these algorithms differed in their use of some diagnostic procedures, triggering a lively debate among the authors. Consequently, they were not systematically used in clinical practice $[3,9,10]$ and were frequently substituted by homemade guidelines in many children's hospitals, which occurred in the USA [11]. The debate on the best approach to infants with FWS has been further stimulated in the past 15 years by evidence of progressively changing epidemiology, aetiology, and characteristics of SBIs [12-14]. Moreover, with time, new biomarkers have become available and their inclusion in the algorithms was thought to potentially significantly improve their diagnostic efficacy [15-17]. The main aim of this study is to describe the historical approach for young infants with FWS and to discuss the impact of recent knowledge regarding this topic on clinical practice.

\section{Materials and Methods}

PubMed was used to search for all of the studies published over the last 35 years using the keywords: "fever without source" or "fever of unknown origin" or "meningitis" or "sepsis" or "urinary tract infection" and "neonate" or "newborn" or "infant $<90$ days of life" or "infant $<3$ months". More than 1400 articles were found, but only those published in English or providing evidence-based data were included in the evaluation.

\section{Traditional Management of Young Infants with Fever without a Source (FWS)}

In the ' 80 s, the evaluation of young infants with FWS was mainly devoted to excluding subjects with SBI to reduce hospitalization rates, laboratory tests, and antibiotic consumption. The first study regarding this approach was published by Dagan et al., and the results led to the formulation of the so-called Rochester criteria [7]. The risk of SBI was deemed low in all infants who otherwise appeared well (i.e., absence of tachypnea, dyspnea, tachycardia, bradycardia, lethargy, and decreased activity/appetite), had no evidence of ear, soft tissue, or skeletal infections, and had white blood cell (WBC) counts between 5000 and $15,000 / \mathrm{mm}^{3}$, bands less than $1500 /$ $\mathrm{mm}^{3}$, and $\leq 10 \mathrm{WBC}$ per high-power field (HPF). Moreover, in cases with diarrhoea, SBI could be excluded if $\leq 5 \mathrm{WBC} /$ HPF could be observed in the stool. This conclusion was drawn from evidence that, among the 144 infants that these authors classified as being low-risk because they met all these criteria, only one ( $0.7 \%)$ had an SBI compared to $22(25 \%)$ of 89 infants that were included in the high-risk group $(p<0.0001)$. The test was calculated to have a sensitivity (SE) of 0.924 (95\% confidence interval (CI), 0.84-0.97), a specificity (SP) of 0.499 (95\% CI, 0.47-0.53), a positive predictive value (PPV) of 0.123 (95\% CI, 0.10-0.16), and a negative predictive value (NPV) of 0.989 (95\% CI, 0.97-1.00). Beginning with these findings, the authors of the Rochester protocol suggested that children included in the low-risk group could remain at home without antibiotics, although a follow-up was required [7]. In contrast, high-risk children should be hospitalized and receive empiric antibiotics together with further analysis and controls [7].

The accuracy of the Rochester criteria for the identification of low-risk young infants was tested in several studies [18-20], which yielded results similar to those reported by Baskin et al. [6]. In detail, the NPV and PPV values reportedly varied from $93.8 \%$ to $98.9 \%$ and $12.3 \%$ to $35.1 \%$, respectively, confirming that only a marginal number of children with SBI could be included in the low-risk group using these criteria, although the identification of those with SBIs was suboptimal and a relevant number of patients without true clinical problems were hospitalized. However, despite these favourable results, some experts considered the Rochester protocol to be inadequate for selection. These criteria could not be applied to premature infants or to children with previously diagnosed medical conditions because these subjects were not included in the study by Baskin et al. [6]. Moreover, neonates were not distinguished from infants, although the risk of SBIs was repeatedly found higher in the first days of life than later in life [20-22]. Finally, Rochester criteria did not consider the risk that neonates and young infants with bacterial meningitis and pneumonia could be included in the low-risk group because these diseases are difficult to diagnose in the first weeks of life if only clinical findings and blood tests are used as suggested by Rochester criteria $[23,24]$.

To overcome these problems, several alternative methods for the identification of febrile children at low or high risk of SBI were developed. The Philadelphia [5] and Boston [6] protocols were devoted to infants aged 29-89 days old, whereas Milwaukee criteria [25] were for children 28-56 days old. Moreover, experts with expertise in pediatrics and infectious diseases or emergency medicine prepared a guideline to approach FWS in neonates [26]. In the Philadelphia, Boston, and Milwaukee statements, clinical criteria, blood tests, and cut-off levels for stratification were quite similar to those included in the Rochester protocol. The urine evaluation was not substantially different, although some additional details for excluding UTIs were included, specifically in the Milwaukee protocol. However, the most relevant difference was the inclusion of cerebrospinal fluid (CSF) testing and, when obtained, the chest radiograph. To be considered low-risk for SBI, an infant had to have a CSF $\mathrm{WBC} / \mathrm{mm}^{3}$ of $<8-10$ and a normal chest radiograph. For neonates, Baraff et al. included a complete evaluation for sepsis, considering blood, urine, and CSF bacterial cultures, which had to all be negative for the low-risk definition [26].

Despite these modifications, these protocols did not significantly increase the ability of Rochester criteria to identify febrile children with and without SBI. Hui et al. evaluated all the literature regarding the diagnostic accuracy of different SBI screenings in febrile infants aged 3 months or younger published between 1950 and September 2010. These authors concluded that all previously cited protocols were similar for correctly identifying infants without SBI [27]. The SE ranged from $84.4 \%$ to $100 \%$, and the NPV ranged from $93.7 \%$ to $100 \%$. However, the SP was low, ranging from $26.6 \%$ to $69.9 \%$. These findings were confirmed when bacteremia and meningitis were considered separately. 
TABLE 1: Historical criteria used in young infants with fever without a source (FWS) to identify those at risk of severe bacterial infection (SBI).

\begin{tabular}{|c|c|c|}
\hline Approach & Clinical and laboratory criteria & Limits \\
\hline Rochester criteria ('80s) & $\begin{array}{l}\text { Low risk of SBI in infants who appeared well } \\
\text { (i.e., absence of tachypnea, dyspnea, tachycardia, } \\
\text { bradycardia, lethargy, and decreased activity/ } \\
\text { appetite), had no evidence of ear, soft tissue, or } \\
\text { skeletal infections, and had WBC counts between } \\
5000 \text { and } 15,000 / \mathrm{mm}^{3} \text {, bands less than } 1500 / \mathrm{mm}^{3} \text {, } \\
\text { and } \leq 10 \mathrm{WBC} \text { per HPF. Moreover, in cases with } \\
\text { diarrhoea, SBI could be excluded if } \leq 5 \mathrm{WBC} / \mathrm{HPF} \\
\text { could be observed in the stool }\end{array}$ & $\begin{array}{c}\text { A relevant number of children without clinical } \\
\text { problems considered at risk of SBI; not applicable } \\
\text { in premature infants and in those with underlying } \\
\text { medical condition }\end{array}$ \\
\hline $\begin{array}{l}\text { Philadelphia, Boston, and } \\
\text { Milwaukee criteria ('90s) }\end{array}$ & $\begin{array}{l}\text { Clinical criteria, blood tests, and cut-off levels } \\
\text { similar to those indicated in the Rochester protocol } \\
\text { plus CSF testing and chest radiograph for the } \\
\text { identification of patients at risk of SBI }\end{array}$ & $\begin{array}{l}\text { Results similar to those observed with Rochester } \\
\text { criteria, although management appeared more } \\
\text { complicated with these protocols }\end{array}$ \\
\hline Baraff criteria ('90s) & $\begin{array}{l}\text { Inclusion of a complete evaluation for sepsis with } \\
\text { blood, urine, and CSF culture in neonates }\end{array}$ & $\begin{array}{l}\text { Limited advantages with the use of universal } \\
\text { CSF testing }\end{array}$ \\
\hline
\end{tabular}

CSF: cerebrospinal fluid; HPF: high-power field; SBI: severe bacterial infection; WBC: white blood cell.

Comparison of bacteremia SE and NPV values among the Rochester [7, 18-20, 28], Boston [29], and Philadelphia $[5,19,30-32]$ criteria revealed SE values ranging from $75.0 \%$ to $100 \%$ and NPV values ranging from $97.1 \%$ and $100 \%$. Regarding meningitis, the Philadelphia criteria $[30,31]$ were found to have excellent SE and NPV (100\%) values but very low values for SP, varying from $24.2 \%$ to $50.7 \%$. Finally, these protocols did not simplify the management of infants. For high-risk subjects, hospitalization and empiric antibiotic administration remained the choice with all the protocols. Low-risk infants tested with Philadelphia criteria were managed according to Rochester criteria [29]. In contrast, management of these infants became more complicated when the Boston [6] and Milwaukee [25] criteria were used because with both of these criteria, infants were sent home with prescriptions for empiric therapy (Boston) or $50 \mathrm{mg} / \mathrm{kg}$ ceftriaxone i.m. (Milwaukee).

Considering the results of the protocols derived from the Rochester protocol, the use of obtaining cultures from infants between 1 and 3 months of age to improve the efficacy of Rochester criteria was strongly criticized by some experts $[33,34]$. Protocols including cultures were considered too complicated and invasive and not utilizable by primary care pediatricians and some hospital emergency departments. Particularly, the use of universal CSF testing was debated. The risk that some children aged 29-59 days with bacterial meningitis could be included in the low-risk group and have delayed diagnoses when CSF testing was lacking was considered practically inexistent. Moreover, it was evidenced that lumbar puncture could lead to higher risks of procedural complications and hospitalization of otherwise low-risk infants [35-37]. However, the low incidence of bacterial meningitis in this age group and the accuracy of Rochester criteria for the identification of children at low risk for SBIs, including bacterial meningitis, were once again confirmed by recent evaluations. Chua et al. conducted a difference-in-difference analysis to compare 7 hospitals with clinical practice guidelines recommending CSF testing for febrile infants aged 29-56 days with 25 hospitals without such guidelines [11]. In these infants, the occurrences of bacterial meningitis diagnosis, mechanical ventilation, central venous catheter placement, extracorporeal membrane oxygenation, and in-hospital mortality were uncommon and similarly distributed between the groups. This was considered evidence that even when not using CSF testing, providers could identify febrile infants at high risk for bacterial meningitis. Similar results were reported by Scarfone et al. [38]. These authors performed a retrospective cohort study in which 1188 febrile infants aged 29-56 days were enrolled. They found that only one child $(0.08 \%)$ had bacterial meningitis. However, he did not meet the Rochester criteria for the low-risk SBI classification and was hospitalized and treated as needed. Unlike children aged 29-59 days, CSF testing to exclude meningitis remained mandatory for neonates, as initially proposed by Baraff et al. [26] and later suggested by the American College of Emergency Physicians [39].

Table 1 summarizes the historical criteria used in young infants with FWS to identify those at risk of SBI.

\section{Adjunctive Diagnostic Tests to Improve the Screening of Young Infants with Fever without a Source (FWS)}

To improve the prediction of SBI in children $<90$ days old, several diagnostic tests used alone or in combination with those previously used were suggested. Evaluation of WBC counts with criteria different from those used in traditional screening methods was found unsatisfactory. Gomez et al. reported that among 3034 infants 22-90 days old that appeared well but presented with FWS, those with leukopenia (WBC $<5000$ cells $/ \mathrm{mm}^{3}$ ) exhibited a lower prevalence of UTIs (8.1\% vs. $14.7 \%$; odds ratio (OR), 0.51 ; $95 \%$ CI, 0.29 - 
$0.88)$ but a similar prevalence of invasive bacterial diseases (2.5\% vs. $2.0 \%$; OR, $1.20 ; 95 \%$ CI, 0.44-3.44) compared with those without leukopenia [40]. Leukopenia was only associated with a high prevalence of bacteremia and meningitis in infants not appearing well, which were included in the high-risk group by definition $(17.8 \%$ vs. $6.9 \%$; OR, 2.90; 95\% CI, 1.06-7.78).

The most studied markers were C-reactive protein (CRP) and procalcitonin (PCT). In most of the studies, both markers had higher SE and SP than WBC count in the identification of SBI. Nosrati et al. reported that WBC counts, absolute neutrophil counts (ANC), and CRP levels were independent laboratory predictors of SBI in a group of 48 infants aged $<90$ days with SBI [41]. However, the accuracy of CRP was significantly higher, as evidenced by the area under the receiver operating characteristic (ROC) curve (AUC).

PCT was frequently found to be even more sensitive than CRP [42-50], although in some studies, the superiority of PCT was evidenced only for the identification of invasive diseases and not for all SBIs [51, 52]. In a recent investigation in which the diagnostic characteristics of the PCT assay, CRP concentrations, WBC counts, and ANC counts for the detection of SBIs were evaluated, it was shown that although the area under the ROC curves for CRP and PCT were similar (AUC 0.81, 95\% CI: 0.83-0.99 vs. AUC 0.80 , 95\% CI: $0.75-0.85 ; p=0.70)$, PCT could more accurately detect bacteremia and bacterial meningitis (AUC 0.91, 95\% CI: $0.83-0.99$ vs. AUC 0.77, 95\% CI: $0.65-0.89, p=0.002$ ) [52]. Moreover, interestingly, no difference was found in neonates compared to older infants. In this study, a cut-off PCT value of $0.3 \mathrm{ng} / \mathrm{mL}$ was associated with a negative likelihood ratio of 0.3 (95\% CI, 0.2-0.5) for identifying SBI and 0.1 (95\% CI, 0.03-0.4) for identifying bacteremia and meningitis. However, a meta-analysis of studies assessing the relevance of the $0.3 \mathrm{ng} / \mathrm{mL}$ PCT cut-off value for the identification of low- and high-risk children with FWS concluded that measuring serum PCT concentrations alone was inferior to the Rochester prediction rules even though it could differentiate some subjects [53].

Considering these limitations, the combination of more biomarkers should have increased the ability of protocols to stratify infants with FWS. Bressan et al. used a laboratory score originally derived and validated by Lacour et al. [54] that combines CRP, PCT, and urine dipstick results [55]. Two points were attributed to $\mathrm{PCT} \geq 0.5 \mathrm{ng} / \mathrm{mL}$ or CRP $\geq 40 \mathrm{mg} / \mathrm{L}$, 4 points to $\mathrm{PCT} \geq 2 \mathrm{ng} / \mathrm{mL}$ or $\mathrm{CRP} \geq 100 \mathrm{mg} / \mathrm{L}$, and 1 point to a positive urine dipstick (i.e., positive leukocyte esterase and/or positive nitrate). A score $\geq 3$ had positive and negative likelihood ratios for SBI prediction of 10.2 (95\% CI, 9.5-10.9) and 0.5 (95\% CI, 0.5-0.5), respectively. When only bacteremia and meningitis were considered, these values dropped to 4.3 (95\% CI, 4.0-4.6) and 0.4 (95\% CI, $0.3-0.5)$, respectively, because $30 \%$ of children with these diseases were not identified, suggesting that the laboratory score was not completely satisfactory for SBI prediction. However, when CRP and PCT were evaluated together with patient and clinical characteristics in the so-called step-bystep approach, better results were obtained [56]. With the step-by-step approach, children were divided according to clinical appearance and age and if they appeared well and were older than 21 days, they underwent laboratory tests for CRP, PCT, and ANC. Comparison of the impacts of laboratory tests, Rochester criteria, and the stepby-step approach revealed that well-appearing infants $<21$ days of age with $\mathrm{CRP}<20 \mathrm{mg} / \mathrm{L}, \mathrm{PCT}<0.5 \mathrm{ng} / \mathrm{mL}$, and ANC $<10,000 / \mathrm{mm}^{3}$ had significantly lower risks of SBI. The SE and NPV of the step-by-step approach were $92 \%$ and $99.3 \%$, respectively, compared to $81.6 \%$ and $98.3 \%$ of the Rochester criteria and $59.8 \%$ and $98.1 \%$ of the laboratory score.

The addition of CRP and PCT to old screening protocols did not significantly reduce the risk that well-appearing younger infants are considered at-risk and receive unneeded therapy. Rochester criteria and other older screening tests have very good NPV values that are only marginally increased by the addition of CRP and PCT. On the contrary, as evidenced by the study by Gomez et al. [15], the addition of these biomarkers seems useful in infants 29-90 days old who are categorized as at-risk with Rochester criteria. In this case, a greater number of patients with true SBI are promptly identified and can receive a more appropriate clinical approach and therapy, particularly when more than one laboratory test is used. Moreover, a greater number of infants without SBI are identified and can be sent home without the need for hospitalization. However, the advantages for neonates are marginal because CRP and PCT are influenced by several factors other than SBIs. Regardless of laboratory test results, neonates with FWS continued to be immediately hospitalized, receive complete evaluation for sepsis, and be treated with antibiotics.

Advances in the identification of SBIs in neonates and young infants might be due to some recently identified biomarkers of sepsis. Studies seem to indicate that soluble triggering receptor expressed on myeloid cells-1 (sTREM-1), interleukin- (IL-) 27, soluble urokinase plasminogen activator receptor (suPAR), neutrophil CD64, presepsin, cell-free DNA (cfDNA), and microRNA (miRNAs) can have relevant roles in this regard $[57,58]$. Most studies concerning these biomarkers have been carried out to evaluate their ability to identify adults with systemic inflammatory response syndrome (SIRS). However, pediatric data are also available for some of these biomarkers. Wong et al. studied IL-27, a cytokine produced by antigen-presenting cells after exposure to microbes and inflammatory stimuli, and found that at serum cut-point values $\geq 5 \mathrm{ng} / \mathrm{mL}$, this marker predicted SBIs in children $<10$ years old, thus meeting pediatric-specific criteria for SIRS, sepsis, and septic shock with SP and PPV values $>90 \%$ and an overall performance generally better than that of PCT [58]. However, the potential role of IL-27 for the stratification of children with suspected infection was only partly confirmed by Hanna et al. [59]. These authors studied children $<15.1$ years old who were admitted to the pediatric intensive care unit for SBI and found the PPV of this biomarker for bacterial infections with FWS to be modest. In contrast, bacteremia was identified in almost all cases with positive blood cultures (SP 95\%; 95\% CI, 92\%-96\%). 
Presepsin is a glycoprotein that serves as a receptor for bacterial lipopolysaccharides and activates proinflammatory responses upon exposure to these agents [60]. Presepsin is considered a potential marker of sepsis in neonates because most variables that commonly affect CRP and PCT in these subjects do not affect presepsin levels [61]. This biomarker was found at higher levels in neonates with late-onset sepsis than in healthy matched subjects (median value, 1295 vs. $562 \mathrm{ng} / \mathrm{L}, p=0.00001)$. The best calculated cut-off value was $885 \mathrm{ng} / \mathrm{L}$, with an SE of 94\%, an SP of $100 \%$, a negative likelihood ratio 0.05 , and an infinite positive likelihood ratio [62].

Further improvements in the identification of SBIs can potentially be obtained using a genomic approach. Because bacteria induce specific host responses that can be detected using a microarray analysis of leukocytes [63-66], analysis of this response could lead to the distinction of bacterial and viral infections. Studies carried out in older children and adults have confirmed this supposition with $>95 \%$ accuracy [67-71]. Moreover, a recent study documented that despite their immature immune systems, even children $<60$ days old respond with RNA biosignatures that permit the differentiation of bacterial and viral infections and discriminate the class of pathogens that cause the infection [72]. A total of 66 classifier genes capable of distinguishing infants with and without SBI were identified, with an SE of $87 \%(95 \%$ CI, 73-95) and an SP of $89 \%$ (95\% CI, 81-83). Bacteremia was associated with 10 classifier genes with an SE of $94 \%$ (95\% CI, 70-100) and SP of 95\% (95\% CI, 88-98).

Recently, new syndromic molecular methods have been developed for rapid etiologic diagnosis of localized or systemic infections. These multiplex real-time polymerase chain reaction tests are able to detect, directly in a single clinical specimen, the most important viral, bacterial, or fungal pathogens responsible for gastrointestinal infections [73], respiratory infections [74], sepsis [75, 76], or meningitis [77] and are characterized by a good diagnostic accuracy. However, their clinical impact and the possibility to include them in the diagnostic algorithms for infants with FWS have not been thoroughly evaluated yet. In this respect, it is noteworthy that both PCT and presepsin have been proved to predict molecular results in adult patients with sepsis [78, 79].

In addition, the Roche SeptiFast ${ }^{\circledR}$ MGRADE PCR with a modified DNA extraction protocol and software-handling tool was tested for the identification of neonatal SBI. Results were compared to blood culture, laboratory biomarkers, and clinical signs of sepsis [80]. Data highlighted that the Roche SeptiFast ${ }^{\circledR}$ MGRADE PCR using a modified DNA extraction protocol appears useful for rapid detection of neonatal sepsis in addition to conventional blood culture. However, this method has a high risk of contamination, does not permit to evaluate antibiotic resistance, and is quite expensive [80].

For all these new approaches, additional studies with larger populations are needed to define the accuracy estimates and to assess their possible use in neonates and infants $<90$ days old with FWS. However, it must be remembered that most SBIs in this age group are attributable to UTIs and these new approaches that are characterized by high costs are mainly devoted to the identification of bacteremia and meningitis, although no information is available on their efficacy in the evaluation of these diseases.

\section{Factors Modifying the Approach to Fever without a Source (FWS) in Neonates and Young Infants}

5.1. Role of Urinary Tract Infection (UTI). When Rochester criteria were developed, bacteremia was the most common SBI in young infants, accounting for approximately $20 \%-30 \%$ of all cases. Meningitis was diagnosed in $0 \%-14 \%$ of the cases, and UTI was observed in $30 \%-55 \%$ of the cases $[5,20]$. A recent analysis of cultures obtained from full-term neonates and infants 1 week to 3 months of age who received care at Kaiser Permanente Northern California from 2007 to 2011 revealed that while no change in the overall SBI rate was observed, the distribution of SBIs has significantly changed in the past 20 years [12]. The prevalence of SBIs due to isolated bacteremia and meningitis was quite low, as it was limited to $6.3 \%$ and $0.2 \%$, respectively. In contrast, UTI was more common, as it was observed in $92.2 \%$ of SBI cases ( $84 \%$ alone and $8.2 \%$ in combination with other infections). The increase in UTI frequency and the consequential need for the early detection of these diseases have raised the problem of the accuracy of traditional UTI test diagnostics. In the first screening tests, UTI was excluded simply based on the absence of significant pyuria, although some UTIs were known to be characterized by little or no pyuria and the threshold suggesting a true UTI was not definitively established [81]. Later, to exclude a UTI, some authors suggested including negative leukocyte esterase and negative nitrite criteria in the urinalysis. However, whether dipstick urinalysis can be an accurate predictor of UTI is debated. In a retrospective study [82] of children from 2 months to 2 years old who presented to the emergency department with fever and a positive urine culture, only $69.9 \%$ of the patients with culture-proven UTIs had a positive urinalysis. Positive leucocyte esterase and nitrite were detected in $63.5 \%$ and $20.9 \%$ of the cases, respectively, suggesting that dipstick analysis adds little to the microscopic evaluation of pyuria independent of the suggested urine WBC thresholds [4-6]. On the contrary, Tzimenatos et al. [83] have recently found that among children aged $\leq 60$ days with FWS and urine culture with $\geq 50,000 \mathrm{CFUs} / \mathrm{mL}$, a positive urinalysis by the presence of any leukocyte esterase, nitrite, or pyuria exhibited sensitivity of 0.94 (95\% CI: $0.91-0.97$ ) and specificity of 0.91 (95\% CI: 0.90-0.91) in all groups. An advance could be assured by the incorporation of urine concentration into the interpretation of automated microscopic urinalysis that is usually performed to evaluate the possible presence of UTI.

A recent study determined which urine WBC threshold was most likely associated with documented UTIs according to urine concentration [84]. The optimal WBC cut-offs were $3 \mathrm{WBC} / \mathrm{HPF}$ in urine samples with specific gravities $<1015$ and $6 \mathrm{WBC} / \mathrm{HPF}$ in urine samples with higher specific gravities. The likely positive and negative ratios were 9.9 and 0.15 for diluted urine and 10.1 and 0.17 for concentrated urine, 
respectively. However, it must be remembered that UTIs are correctly diagnosed only by urine culture, a number of young infants with UTIs have negative urinalysis, and only about $5 \%$ of UTIs in pediatric-aged children are associated with bacteremia and have urosepsis [85]. It is worth noting that in UTI matrix-assisted time-of-flight mass spectrometry performed directly in urine is able to identify pathogens in about 1 hour [86], suggesting that, in the near future, this technology could be included in the routine diagnostics, anticipating culture results.

5.2. Role of Viral Infection. The study that had led to the definition of Rochester criteria also reported that a relevant number of young infants included in both the low- and high-risk groups had viral infections [7]. Unfortunately, this information could not be included among the criteria for screening because of the lack of timely results. As later evidence, the incorporation of viral information into the risk criteria could have significantly improved the stratification capacity of the protocol. Several studies have highlighted that association between confirmed viral infections and most SBIs, including bacteremia and meningitis, is generally uncommon. Only UTI prevalence was found to not always be significantly influenced by the coexistence of viral infection. Byington et al. studied the distribution of infections due to enteroviruses, respiratory viruses, rotaviruses, and herpesviruses among 1385 infants aged $<90$ days with FWS who were classified as low- or high-risk for SBIs according to Rochester criteria [87]. These authors reported that the SBI occurrence was significantly lower in infants with viral infections than in those without $(4.2 \%$ vs. $12.3 \%$; $p<0.0001)$. High-risk virus-positive patients had significantly fewer SBIs than high-risk virus-negative patients $(5.5 \%$ vs. $16.7 \%$; $p<0.0001)$. When compared with high-risk virusnegative patients, high-risk virus-positive patients were less likely to have bacteremia, UTIs, or soft tissue infections and high-risk virus-positive patients had bacteremia occurrences similar to those of low-risk patients $(0.92 \%$ vs. $1.97 \%$; $p=0.24)$ but higher occurrences of UTI $(3.7 \%$ vs. $1 \%$; $p=0.002$ ).

The relationship between RSV infection and the development of SBIs was investigated by Levine et al. in a group of 1248 febrile infants $\leq 60$ days old [88]. SBIs were significantly more common in RSV-negative children $(12.5 \%$; $95 \% \mathrm{CI}$, 10.5-14.8) than in those with RSV infection (7.0\%; 95\% CI, 4.1-10.9; relative risk (RR), 0.6 ; 95\% CI, $0.3-0.9$ ). These findings were partly confirmed when single SBIs were analysed, as RSV-positive infants had a lower rate of bacteremia than RSV-negative infants, although the differences were not significant ( $1.1 \%$ vs. $2.3 \%$; risk difference, $1.2 \%$; $95 \% \mathrm{CI}$, $-0.4 \%$ to $2.7 \%)$. No RSV-positive infants had bacterial meningitis ( 0 of $251 ; 95 \%$ CI, $0 \%-1.2 \%$ ). However, more than $5 \%$ of these patients were found to suffer from UTIs. The very low risk of SBIs in infants suffering from bronchiolitis and RSV infection was further evidenced by Ralston et al. [89]. These authors analysed all the studies published until December 31, 2010, in which rates of UTI, bacteremia, and meningitis in younger infants with bronchiolitis and RSV infection had been evaluated. It was found that the weighted rate of UTIs in the 11 studies analysed was 3.3\% (95\% CI, 1.9-5.7). Bacteremia was observed in 3 of 11 studies. No case of meningitis was reported in any of the studies. Similar results were reported when the association between influenza and SBIs was evaluated. In a study testing 809 children $\leq 60$ days old, the risk of SBI was significantly higher in subjects without influenza than in those with this infection $(13.3 \%$, 95\% CI: $10.9-16.1$ vs. $2.5 \%$, 95\% CI: $0.5-7.2 ; p<0.001)$ [90]. Bacteremia and meningitis were diagnosed in $2.2 \%$ and $0.9 \%$ of influenza-negative infants, respectively, and in no infants with influenza, with no statistically significant differences between the groups. However, the prevalence of UTI was significantly higher in influenza-negative children than in those that were influenza-positive (10.8\%, 95\% CI: $8.6 \%-$ $13.3 \%$ vs. $2.4 \%$, 95\% CI: $0.5-6.9 ; p=0.002$ ).

All these findings provide evidence that when several rapid methods for detecting viruses are available, the addition of viral diagnostics to Rochester criteria could permit to better classify patients regarding their individual risk for SBI. For a complete evaluation, the herpes simplex virus and parechovirus must be studied together with traditionally tested viruses, as these viruses can be associated with very severe, life-threatening clinical manifestations. Recent data have highlighted the relevance of these agents as causes of FWS in neonates and young infants $[91,92]$. Virus detection can lead to significant advantages for both infants and the health care system. The implementation of an evidencebased care process model for the care of febrile infants, including viral tests, was associated with the increased delivery of evidence-based care and the reduction of hospital stay, time exposed to antibiotics, and general costs of health services [93].

However, it cannot be forgotten that evidence of a coexisting viral infection does not exclude the presence of an SBI, although this evidence is useful for better selection. A small, but significant, number of neonates and young infants are not correctly categorized even with the addition of viral tests. Moreover, viral detection in respiratory secretions does not systematically indicate that the virus is the true cause of the actual disease. Several studies have demonstrated that some respiratory viruses are shed for several days after the disease is resolved $[94,95]$, which can mask the true aetiology of the disease.

5.3. Changing the Distribution of Infectious Bacteria. In older studies, numerous SBIs, particularly those diagnosed in neonates, were due to group B Streptococcus (GBS) and Listeria monocytogenes. However, recent studies have clearly evidenced that rates of early-onset GBS and Listeria monocytogenes infections have been significantly reduced. Moreover, significant modifications in the distribution of bacterial pathogens causing late-onset infections have been reported. Together with a relevant reduction of late-onset GBS infections and the almost complete disappearance of Listeria monocytogenes infection, epidemiological studies have clearly shown that Gram-negative rods, mainly Escherichia coli, were the most common causes of SBIs in children aged 7-90 days, as they were detected not only in UTIs but also in bacteremia and meningitis [96, 97]. The cause for this 
shift is not completely known. The reduction of SBI cases due to Haemophilus influenzae type b and Streptococcus pneumoniae in young infants might be due to the herd immunity effect resulting from the use of conjugate vaccines against these pathogens in the pediatric immunization schedule [98-100]. The decline in the number of early-onset GBS SBIs has been ascribed to the screening of pregnant women in combination with intrapartum prophylactic antibiotic treatment recommended by several health authorities [98-100]. However, as reported by a Cochrane review [101], if effective, these measures reduce the incidences of early-onset GBS infection, whereas the epidemiology of late-onset GBS infection is not influenced. Regarding Listeria monocytogenes infection, antibiotic prophylaxis against GBS could have played a role in reducing the number of SBIs caused by this pathogen [102]. Penicillin $G$ and ampicillin are the drugs of choice for prophylaxis against GBS [103], and for years, most Listeria monocytogenes strains have been found to be sensitive to ampicillin, although no evidence for ampicillin functioning as prophylaxis against this pathogen in pregnant women exists. However, the therapeutic association with gentamicin is suggested to assure effective intracellular concentrations [104]. However, available data have indicated a relationship between the decrease of early-onset GBS infection and the reduction of Listeria monocytogenes $[105,106]$ infection rates, although evidence of an impact on late-onset SBIs is lacking.

However, independent from the shifting reasons, the most important point regarding GBS antibiotic treatment is that emerging Gram-negative rods were recently found to be frequently resistant to ampicillin, particularly when cultured from children born to mothers who received this antibiotic for prophylaxis. This has raised concerns not only for the GBS prophylaxis antibiotic of choice but also for the treatment of children at high-risk for SBIs. In a relevant number of cases, use of the association between ampicillin and gentamicin, traditionally considered the drugs of choice to treat bacterial infections in neonates and younger infants, leaves a child with only gentamicin treatment $[12,20]$. Because the use of the third generation cephalosporins is debatable, at least in neonatology, due to possibly increased neonatal mortality when these drugs are used as empirical therapy [107], only a continuous and detailed analysis of the local resistance patterns of common infectious pathogens can lead to effective antibiotic prescriptions.

\section{Conclusions}

The selection of neonates and young infants who are $<3$ months old with FWS who are at risk for SBI remains a problem without a definitive solution. The old Rochester criteria and the protocols derived from this remain effective for identifying young infants between 29 and 60 days old who do not have SBIs. The risk that an invasive disease is misdiagnosed is very low, especially today when the incidences of bacteremia and meningitis are reduced and most SBIs are UTIs. However, a more complex approach including the use of CRP and PCT can permit to identify a greater number of children with FWS that really have SBI and need immediate prompt hospitalization and adequate therapy. The step-by-step protocol previously cited seems presently the best solution to assure an adequate approach to all the children $<3$ months with FWS. However, it is highly likely that, in the future, more effective methods to differentiate low- and high-risk children with FWS such as molecular techniques and new effective biomarkers will become available.

The approach in evaluating neonates is significantly more complicated, as their risk of SBIs, including bacteremia and meningitis, remains relevant and none of the suggested approaches can reduce the risk of dramatic mistakes. This is the main reason that most experts suggest obtaining cultures and prescribing immediate antibiotic treatment for neonatal children with FWS. However, the best antibiotic must be carefully selected considering the changing epidemiology and increasing antibiotic resistance of the most common infectious bacteria.

\section{Conflicts of Interest}

The authors declare that they have no conflicts of interest.

\section{Acknowledgments}

This review was partially supported by a grant from the World Association for Infectious Diseases and Immunological Disorders (WAidid 2016_09).

\section{References}

[1] National Institute for Health and Care Excellence (NICE), "Fever in under 5s: assessment and initial managementSeptember 2018, https://www.nice.org.uk/guidance/cg160/ chapter/1-Recommendations.

[2] J. W. Antoon, N. M. Potisek, and J. A. Lohr, "Pediatric fever of unknown origin," Pediatrics in Review, vol. 36, no. 9, pp. 380-391, 2015.

[3] P. L. Aronson, C. Thurm, E. R. Alpern et al., "Variation in care of the febrile young infant $<90$ days in US pediatric emergency departments," Pediatrics, vol. 134, no. 4, pp. 667-677, 2014.

[4] A. G. DePorre, P. L. Aronson, and R. J. McCulloh, "Facing the ongoing challenge of the febrile young infant," Critical Care, vol. 21 , no. 1, p. $68,2017$.

[5] M. D. Baker, L. M. Bell, and J. R. Avner, "Outpatient management without antibiotics of fever in selected infants," The New England Journal of Medicine, vol. 329, no. 20, pp. 1437-1441, 1993.

[6] M. N. Baskin, E. J. O’Rourke, and G. R. Fleisher, “Outpatient treatment of febrile infants 28 to 89 days of age with intramuscular administration of ceftriaxone," The Journal of Pediatrics, vol. 120, no. 1, pp. 22-27, 1992.

[7] R. Dagan, K. R. Powell, C. B. Hall, and M. A. Menegus, "Identification of infants unlikely to have serious bacterial infection although hospitalized for suspected sepsis," The Journal of Pediatrics, vol. 107, no. 6, pp. 855-860, 1985. 
[8] K. R. Powell, "Evaluation and management of febrile infants younger than 60 days of age," The Pediatric Infectious Disease Journal, vol. 9, no. 3, pp. 153-157, 1990.

[9] P. L. Aronson, C. Thurm, D. J. Williams et al., "Association of clinical practice guidelines with emergency department management of febrile infants $\leq 56$ days of age," Journal of Hospital Medicine, vol. 10, no. 6, pp. 358-365, 2015.

[10] S. Jain, J. Cheng, E. R. Alpern et al., "Management of febrile neonates in US pediatric emergency departments," Pediatrics, vol. 133, no. 2, pp. 187-195, 2014.

[11] K.-P. Chua, M. I. Neuman, J. M. McWilliams et al., "Association between clinical outcomes and hospital guidelines for cerebrospinal fluid testing in febrile infants aged 29-56 days," The Journal of Pediatrics, vol. 167, no. 6, pp. 1340-1346.e9, 2015.

[12] T. L. Greenhow, Y. Y. Hung, A. M. Herz, E. Losada, and R. H. Pantell, "The changing epidemiology of serious bacterial infections in young infants," The Pediatric Infectious Disease Journal, vol. 33, no. 6, pp. 595-599, 2014.

[13] R. Leazer, A. M. Perkins, K. Shomaker, and B. Fine, "A meta-analysis of the rates of Listeria monocytogenes and Enterococcus in febrile infants," Hospital Pediatrics, vol. 6, no. 4, pp. 187-195, 2016.

[14] J. R. Verani and S. J. Schrag, "Group B streptococcal disease in infants: progress in prevention and continued challenges," Clinics in Perinatology, vol. 37, no. 2, pp. 375-392, 2010.

[15] B. Gomez, S. Mintegi, S. Bressan et al., "Validation of the "step-by-step" approach in the management of young febrile infants," Pediatrics, vol. 138, no. 2, article e20154381, 2016.

[16] P. Montaldo, R. Rosso, A. Santantonio, G. Chello, and P. Giliberti, "Presepsin for the detection of early-onset sepsis in preterm newborns," Pediatric Research, vol. 81, no. 2, pp. 329-334, 2017.

[17] W. J. Hanna, Z. Berrens, T. Langner, P. Lahni, and H. R. Wong, "Interleukin-27: a novel biomarker in predicting bacterial infection among the critically ill," Critical Care, vol. 19, no. 1, p. 378, 2015.

[18] P. C. Ferrera, J. M. Bartfield, and H. S. Snyder, "Neonatal fever: utility of the Rochester criteria in determining low risk for serious bacterial infections," The American Journal of Emergency Medicine, vol. 15, no. 3, pp. 299-302, 1997.

[19] G. Garra, S. J. Cunningham, and E. F. Crain, "Reappraisal of criteria used to predict serious bacterial illness in febrile infants less than 8 weeks of age," Academic Emergency Medicine, vol. 12, no. 10, pp. 921-925, 2005.

[20] J. A. Jaskiewicz, C. A. McCarthy, A. C. Richardson et al., "Febrile infants at low risk for serious bacterial infection-an appraisal of the Rochester criteria and implications for management. Febrile Infant Collaborative Study Group," Pediatrics, vol. 94, no. 3, pp. 390-396, 1994.

[21] C. L. Byington, K. K. Rittichier, K. E. Bassett et al., "Serious bacterial infections in febrile infants younger than 90 days of age: the importance of ampicillin-resistant pathogens," Pediatrics, vol. 111, no. 5, pp. 964-968, 2003.

[22] R. H. Pantell, T. B. Newman, J. Bernzweig et al., "Management and outcomes of care of fever in early infancy," JAMA, vol. 291, no. 10, pp. 1203-1212, 2004.

[23] H. P. Garges, M. A. Moody, C. M. Cotten et al., "Neonatal meningitis: what is the correlation among cerebrospinal fluid cultures, blood cultures, and cerebrospinal fluid parameters?," Pediatrics, vol. 117, no. 4, pp. 1094-1100, 2006.
[24] T. A. Hooven and R. A. Polin, "Pneumonia," Seminars in Fetal and Neonatal Medicine, vol. 22, no. 4, pp. 206-213, 2017.

[25] W. A. Bonadio, E. Hagen, J. Rucka, K. Shallow, P. Stommel, and D. Smith, "Efficacy of a protocol to distinguish risk of serious bacterial infection in the outpatient evaluation of febrile young infants," Clinical Pediatrics, vol. 32, no. 7, pp. 401-404, 1993.

[26] L. J. Baraff, J. W. Bass, G. R. Fleisher et al., "Practice guideline for the management of infants and children 0 to 36 months of age with fever without source," Annals of Emergency Medicine, vol. 22, no. 7, pp. 1198-1210, 1993.

[27] C. Hui, G. Neto, A. Tsertsvadze, F. Yazdi, A. C. Tricco, S. Tsouros et al., "Diagnosis and management of febrile infants (0-3 months)," Evidence Report/Technology Assessment No. 205, Agency for Healthcare Research and Quality, Rockville, MD, USA, 2012.

[28] R. Dagan, S. Sofer, M. Phillip, and E. Shachak, "Ambulatory care of febrile infants younger than 2 months of age classified as being at low risk for having serious bacterial infections," The Journal of Pediatrics, vol. 112, no. 3, pp. 355-360, 1988.

[29] H. A. Kadish, B. Loveridget, J. Tobeyt, R. G. Bolte, and H. M. Corneli, "Applying outpatient protocols in febrile infants 1-28 days of age: can the threshold be lowered?," Clinical Pediatrics, vol. 39, no. 2, pp. 81-88, 2000.

[30] M. D. Baker, L. M. Bell, and J. R. Avner, "The efficacy of routine outpatient management without antibiotics of fever in selected infants," Pediatrics, vol. 103, no. 3, pp. 627-631, 1999.

[31] M. D. Baker and L. M. Bell, "Unpredictability of serious bacterial illness in febrile infants from birth to 1 month of age," Archives of Pediatrics \& Adolescent Medicine, vol. 153, no. 5, pp. 508-511, 1999.

[32] M. D. Baker, "Evaluation and management of infants with fever," Pediatric Clinics of North America, vol. 46, no. 6, pp. 1061-1072, 1999.

[33] L. J. Baraff, "Outpatient management of fever in selected infants," The New England Journal of Medicine, vol. 330, no. 13, pp. 938-940, 1994.

[34] R. F. Perry and A. P. Garlisi, "Outpatient management of fever in selected infants," The New England Journal of Medicine, vol. 330, p. 939, 1994.

[35] S. De, A. Tong, D. Issacs, and J. C. Craig, "Parental perspectives on evaluation and management of fever in young infants: an interview study," Archives of Disease in Childhood, vol. 99, no. 8, pp. 717-723, 2014.

[36] R. W. Evans, "Complications of lumbar puncture," Neurologic Clinics, vol. 16, no. 1, pp. 83-105, 1998.

[37] E. W. Pingree, A. A. Kimia, and L. E. Nigrovic, "The effect of traumatic lumbar puncture on hospitalization rate for febrile infants 28 to 60 days of age," Academic Emergency Medicine, vol. 22, no. 2, pp. 240-243, 2015.

[38] R. Scarfone, A. Murray, P. Gala, and F. Balamuth, "Lumbar puncture for all febrile infants 29-56 days old: a retrospective cohort reassessment study," The Journal of Pediatrics, vol. 187, pp. 200-205.e1, 2017.

[39] American College of Emergency Physicians Clinical Policies Committee and American College of Emergency Physicians Clinical Policies Subcommittee on Pediatric Fever, "Clinical policy for children younger than three years presenting to the emergency department with fever," Annals of Emergency Medicine, vol. 42, no. 4, pp. 530-545, 2003. 
[40] B. Gomez, S. Mintegi, and J. Benito, "A prospective multicenter study of leukopenia in infants under 90 days of age with fever without source," The Pediatric Infectious Disease Journal, vol. 35, no. 1, pp. 1-29, 2016.

[41] A. Nosrati, A. Ben Tov, and S. Reif, "Diagnostic markers of serious bacterial infections in febrile infants younger than 90 days old," Pediatrics International, vol. 56, no. 1, pp. 47-52, 2014.

[42] B. Andreola, S. Bressan, S. Callegaro, A. Liverani, M. Plebani, and L. Da Dalt, "Procalcitonin and C-reactive protein as diagnostic markers of severe bacterial infections in febrile infants and children in the emergency department," The Pediatric Infectious Disease Journal, vol. 26, no. 8, pp. 672-677, 2007.

[43] A. Fernández López, C. Luaces Cubells, J. J. García García, and J. Fernández Pou, "Procalcitonin in pediatric emergency departments for the early diagnosis of invasive bacterial infections in febrile infants: results of a multicenter study and utility of a rapid qualitative test for this marker," The Pediatric Infectious Disease Journal, vol. 22, no. 10, pp. 895904, 2003.

[44] F. Dubos, F. Moulin, V. Gajdos et al., "Serum procalcitonin and other biologic markers to distinguish between bacterial and aseptic meningitis," The Journal of Pediatrics, vol. 149, no. 1, pp. 72-76, 2006.

[45] A. G. Lacour, A. Gervaix, S. A. Zamora et al., "Procalcitonin, IL-6, IL-8, IL-1 receptor antagonist and C-reactive protein as identificators of serious bacterial infections in children with fever without localising signs," European Journal of Pediatrics, vol. 160, no. 2, pp. 95-100, 2001.

[46] A. G. Galetto-Lacour, S. A. Zamora, B. Andreola et al., "Validation of a laboratory risk index score for the identification of severe bacterial infection in children with fever without source," Archives of Disease in Childhood, vol. 95, no. 12, pp. 968-973, 2010.

[47] D. Gendrel, J. Raymond, J. Coste et al., "Comparison of procalcitonin with C-reactive protein, interleukin 6 and interferon-alpha for differentiation of bacterial vs. viral infections," The Pediatric Infectious Disease Journal, vol. 18, no. 10, pp. 875-881, 1999.

[48] S. Leroy, A. Fernandez-Lopez, R. Nikfar et al., "Association of procalcitonin with acute pyelonephritis and renal scars in pediatric UTI," Pediatrics, vol. 131, no. 5, pp. 870-879, 2013.

[49] F. Moulin, J. Raymond, M. Lorrot et al., "Procalcitonin in children admitted to hospital with community acquired pneumonia," Archives of Disease in Childhood, vol. 84, no. 4, pp. 332-336, 2001.

[50] B. Gomez, S. Bressan, S. Mintegi et al., "Diagnostic value of procalcitonin in well-appearing young febrile infants," Pediatrics, vol. 130, no. 5, pp. 815-822, 2012.

[51] M. G. Díaz, R. P. García, D. B. Gamero et al., "Lack of accuracy of biomarkers and physical examination to detect bacterial infection in febrile infants," Pediatric Emergency Care, vol. 32, no. 10, pp. 664-668, 2016.

[52] K. Milcent, S. Faesch, C. Gras-le Guen et al., "Use of procalcitonin assays to predict serious bacterial infection in young febrile infants," JAMA Pediatrics, vol. 170, no. 1, pp. 62-69, 2016.

[53] J. T. England, M. T. Del Vecchio, and S. C. Aronoff, "Use of serum procalcitonin in evaluation of febrile infants: a meta-analysis of 2317 patients," The Journal of Emergency Medicine, vol. 47, no. 6, pp. 682-688, 2014.
[54] A. G. Lacour, S. A. Zamora, and A. Gervaix, "A score identifying serious bacterial infections in children with fever without source," The Pediatric Infectious Disease Journal, vol. 27, no. 7, pp. 654-656, 2008.

[55] S. Bressan, B. Gomez, S. Mintegi et al., "Diagnostic performance of the lab-score in predicting severe and invasive bacterial infections in well-appearing young febrile infants," The Pediatric Infectious Disease Journal, vol. 31, no. 12, pp. 1239-1244, 2012.

[56] S. Mintegi, S. Bressan, B. Gomez et al., "Accuracy of a sequential approach to identify young febrile infants at low risk for invasive bacterial infection," Emergency Medicine Journal, vol. 31, no. e1, pp. e19-e24, 2014.

[57] M. Sandquist and H. R. Wong, "Biomarkers of sepsis and their potential value in diagnosis, prognosis and treatment," Expert Review of Clinical Immunology, vol. 10, no. 10, pp. 1349-1356, 2014.

[58] H. R. Wong, N. Z. Cvijanovich, M. Hall et al., "Interleukin-27 is a novel candidate diagnostic biomarker for bacterial infection in critically ill children," Critical Care, vol. 16, no. 5, article R213, 2012.

[59] H. R. Wong, N. Z. Cvijanovich, M. Hall et al., "Interleukin-27 is a novel candidate diagnostic biomarker for bacterial infection in critically ill children," Critical Care, vol. 16, no. 5, article R213, 2012.

[60] M. Ulla, E. Pizzolato, M. Lucchiari et al., "Diagnostic and prognostic value of presepsin in the management of sepsis in the emergency department: a multicenter prospective study," Critical Care, vol. 17, no. 4, article R168, 2013.

[61] L. Pugni, C. Pietrasanta, S. Milani et al., "Presepsin (soluble CD14 subtype): reference ranges of a new sepsis marker in term and preterm neonates," PLoS One, vol. 10, no. 12, article e0146020, 2015.

[62] C. Poggi, T. Bianconi, E. Gozzini, M. Generoso, and C. Dani, "Presepsin for the detection of late-onset sepsis in preterm newborns," Pediatrics, vol. 135, no. 1, pp. 68-75, 2015.

[63] X. Hu, J. Yu, S. D. Crosby, and G. A. Storch, "Gene expression profiles in febrile children with defined viral and bacterial infection," Proceedings of the National Academy of Sciences of the United States of America, vol. 110, no. 31, pp. 1279212797, 2013.

[64] O. Ramilo, W. Allman, W. Chung et al., "Gene expression patterns in blood leukocytes discriminate patients with acute infections," Blood, vol. 109, no. 5, pp. 2066-2077, 2007.

[65] D. A. Relman, "New technologies, human-microbe interactions, and the search for previously unrecognized pathogens," The Journal of Infectious Diseases, vol. 186, Supplement 2, pp. S254-S258, 2002.

[66] A. K. Zaas, M. Chen, J. Varkey et al., "Gene expression signatures diagnose influenza and other symptomatic respiratory viral infections in humans," Cell Host \& Microbe, vol. 6, no. 3, pp. 207-217, 2009.

[67] S. T. Anderson, M. Kaforou, A. J. Brent et al., "Diagnosis of childhood tuberculosis and host RNA expression in Africa," The New England Journal of Medicine, vol. 370, no. 18, pp. 1712-1723, 2014.

[68] M. I. Ardura, R. Banchereau, A. Mejias et al., "Enhanced monocyte response and decreased central memory $\mathrm{T}$ cells in children with invasive Staphylococcus aureus infections," PLoS One, vol. 4, no. 5, article e5446, 2009. 
[69] R. Banchereau, A. Jordan-Villegas, M. Ardura et al., "Host immune transcriptional profiles reflect the variability in clinical disease manifestations in patients with Staphylococcus aureus infections," PLoS One, vol. 7, no. 4, article e34390, 2012.

[70] J. A. Herberg, M. Kaforou, S. Gormley et al., "Transcriptomic profiling in childhood H1N1/09 influenza reveals reduced expression of protein synthesis genes," The Journal of Infectious Diseases, vol. 208, no. 10, pp. 1664-1668, 2013.

[71] M. Kaforou, V. J. Wright, T. Oni et al., "Detection of tuberculosis in HIV-infected and -uninfected African adults using whole blood RNA expression signatures: a case-control study," PLoS Medicine, vol. 10, no. 10, article e1001538, 2013.

[72] P. Mahajan, N. Kuppermann, A. Mejias et al., "Association of RNA biosignatures with bacterial infections in febrile infants aged 60 days or younger," JAMA, vol. 316, no. 8, pp. 846-857, 2016.

[73] A. Steyer, M. Jevšnik, M. Petrovec et al., "Narrowing of the diagnostic gap of acute gastroenteritis in children 0-6 years of age using a combination of classical and molecular techniques, delivers challenges in syndromic approach diagnostics," The Pediatric Infectious Disease Journal, vol. 35, no. 9, pp. e262-e270, 2016.

[74] J. H. K. Chen, H. Y. Lam, C. C. Y. Yip et al., "Clinical evaluation of the new high-throughput Luminex NxTAG respiratory pathogen panel assay for multiplex respiratory pathogen detection," Journal of Clinical Microbiology, vol. 54, no. 7, pp. 1820-1825, 2016.

[75] C. Calitri, M. Denina, C. Scolfaro et al., "Etiological diagnosis of bloodstream infections through a multiplex real-time polymerase chain reaction test in pediatric patients: a case series from a tertiary Italian hospital," Infectious Diseases, vol. 47, no. 2, pp. 73-79, 2015.

[76] B. Lucignano, S. Ranno, O. Liesenfeld et al., "Multiplex PCR allows rapid and accurate diagnosis of bloodstream infections in newborns and children with suspected sepsis," Journal of Clinical Microbiology, vol. 49, no. 6, pp. 2252-2258, 2011.

[77] H. S. Arora, B. I. Asmar, H. Salimnia, P. Agarwal, S. Chawla, and N. Abdel-Haq, "Enhanced identification of group B Streptococcus and Escherichia coli in young infants with meningitis using the biofire filmarray meningitis/encephalitis panel," The Pediatric Infectious Disease Journal, vol. 36, no. 7, pp. 685-687, 2017.

[78] C. Leli, M. Ferranti, U. Marrano et al., "Diagnostic accuracy of presepsin (sCD14-ST) and procalcitonin for prediction of bacteraemia and bacterial DNAaemia in patients with suspected sepsis," Journal of Medical Microbiology, vol. 65, no. 8, pp. 713-719, 2016.

[79] D. Mihajlovic, S. Brkic, A. Uvelin, B. Draskovic, and V. Vrsajkov, "Use of presepsin and procalcitonin for prediction of SeptiFast results in critically ill patients," Journal of Critical Care, vol. 40, pp. 197-201, 2017.

[80] J. Straub, H. Paula, M. Mayr et al., "Diagnostic accuracy of the ROCHE Septifast PCR system for the rapid detection of blood pathogens in neonatal sepsis-a prospective clinical trial," PLoS One, vol. 12, no. 11, article e0187688, 2017.

[81] S. H. Kim, S. Y. Lyu, H. Y. Kim, S. E. Park, and S. Y. Kim, "Can absence of pyuria exclude urinary tract infection in febrile infants? About 2011 AAP guidelines on UTI," Pediatrics International, vol. 58, no. 6, pp. 472-475, 2016.
[82] M. Waseem, J. Chen, G. Paudel et al., "Can a simple urinalysis predict the causative agent and the antibiotic sensitivities?," Pediatric Emergency Care, vol. 30, no. 4, pp. 244-247, 2014.

[83] L. Tzimenatos, P. Mahajan, P. S. Dayan et al., "Accuracy of the urinalysis for urinary tract infections in febrile infants 60 days and younger," Pediatrics, vol. 141, no. 2, article e20173068, 2018.

[84] P. P. Chaudhari, M. C. Monuteaux, and R. G. Bachur, "Urine concentration and pyuria for identifying UTI in infants," Pediatrics, vol. 138, no. 5, article e20162370, 2016.

[85] O. Megged, "Bacteremic vs nonbacteremic urinary tract infection in children," The American Journal of Emergency Medicine, vol. 35, no. 1, pp. 36-38, 2017.

[86] Y. Zboromyrska, E. Rubio, I. Alejo et al., "Development of a new protocol for rapid bacterial identification and susceptibility testing directly from urine samples," Clinical Microbiology and Infection, vol. 22, no. 6, pp. 561.e1-561.e6, 2016.

[87] C. L. Byington, F. R. Enriquez, C. Hoff et al., "Serious bacterial infections in febrile infants 1 to 90 days old with and without viral infections," Pediatrics, vol. 113, no. 6, pp. 1662-1666, 2004.

[88] D. A. Levine, S. L. Platt, P. S. Dayan et al., "Risk of serious bacterial infection in young febrile infants with respiratory syncytial virus infections," Pediatrics, vol. 113, no. 6, pp. 1728-1734, 2004.

[89] S. Ralston, V. Hill, and A. Waters, "Occult serious bacterial infection in infants younger than 60 to 90 days with bronchiolitis: a systematic review," Archives of Pediatrics and Adolescent Medicine, vol. 165, no. 10, pp. 951-956, 2011.

[90] W. I. Krief, D. A. Levine, S. L. Platt et al., "Influenza virus infection and the risk of serious bacterial infections in young febrile infants," Pediatrics, vol. 124, no. 1, pp. 30-39, 2009.

[91] S. H. James and D. W. Kimberlin, "Neonatal herpes simplex virus infection," Infectious Disease Clinics of North America, vol. 29, no. 3, pp. 391-400, 2015.

[92] Y. Aizawa, R. Izumita, and A. Saitoh, "Human parechovirus type 3 infection: an emerging infection in neonates and young infants," Journal of Infection and Chemotherapy, vol. 23, no. 7, pp. 419-426, 2017.

[93] C. L. Byington, C. C. Reynolds, K. Korgenski et al., "Costs and infant outcomes after implementation of a care process model for febrile infants," Pediatrics, vol. 130, no. 1, pp. e16-e24, 2012.

[94] N. Principi, A. Zampiero, M. Gambino et al., "Prospective evaluation of rhinovirus infection in healthy young children," Journal of Clinical Virology, vol. 66, pp. 83-89, 2015.

[95] M. J. Loeffelholz, R. Trujillo, R. B. Pyles et al., "Duration of rhinovirus shedding in the upper respiratory tract in the first year of life," Pediatrics, vol. 134, no. 6, pp. 1144-1150, 2014.

[96] M. Mischler, M. S. Ryan, J. K. Leyenaar et al., "Epidemiology of bacteremia in previously healthy febrile infants: a followup study," Hospital Pediatrics, vol. 5, no. 6, pp. 293-300, 2015.

[97] M. M. Koopmans, M. W. Bijlsma, M. C. Brouwer, D. van de Beek, and A. van der Ende, "Listeria monocytogenes meningitis in the Netherlands, 1985-2014: a nationwide surveillance study," Journal of Infection, vol. 75, no. 1, pp. 12-19, 2017.

[98] G. C. Di Renzo, P. Melin, A. Berardi et al., "Intrapartum GBS screening and antibiotic prophylaxis: a European consensus 
conference," The Journal of Maternal-Fetal \& Neonatal Medicine, vol. 28, no. 7, pp. 766-782, 2015.

[99] J. R. Verani, L. McGee, and S. J. Schrag, "Prevention of perinatal group B streptococcal disease: revised guidelines from CDC, 2010," MMWR Recommendations and Reports, vol. 59, no. RR-10, pp. 1-36, 2010.

[100] S. Esposito, N. Principi, and ESCMID Vaccine Study Group (EVASG), "Direct and indirect effects of the 13-valent pneumococcal conjugate vaccine administered to infants and young children," Future Microbiology, vol. 10, no. 10, pp. 1599-1607, 2015.

[101] A. Ohlsson and V. S. Shah, "Intrapartum antibiotics for known maternal group B streptococcal colonization," Cochrane Database of Systematic Reviews, vol. 6, article CD007467, 2014.

[102] L. A. Cioffredi and R. Jhaveri, "Evaluation and management of febrile children: a review," JAMA Pediatrics, vol. 170, no. 8, pp. 794-800, 2016.

[103] Centers for Diseases Control and Prevention (CDC), "Algorithm for secondary prevention of early-onset group B streptococcal (GBS) disease among newborns," July 2017, https:// www.cdc.gov/groupbstrep/guidelines/downloads/ recommended-regimens.pdf.

[104] H. Hof, "Listeriosis: therapeutic options," FEMS Immunology and Medical Microbiology, vol. 35, no. 3, pp. 203-205, 2003.

[105] K. Watt, E. Waddle, and R. Jhaveri, "Changing epidemiology of serious bacterial infections in febrile infants without localizing signs," PLoS One, vol. 5, no. 8, article e12448, 2010.

[106] B. Lee, J. G. Newland, and R. Jhaveri, "Reductions in neonatal listeriosis: "collateral benefit" of group B streptococcal prophylaxis?," The Journal of Infection, vol. 72, no. 3, pp. 317-323, 2016.

[107] R. H. Clark, B. T. Bloom, A. R. Spitzer, and D. R. Gerstmann, "Empiric use of ampicillin and cefotaxime, compared with ampicillin and gentamicin, for neonates at risk for sepsis is associated with an increased risk of neonatal death," Pediatrics, vol. 117, no. 1, pp. 67-74, 2006. 


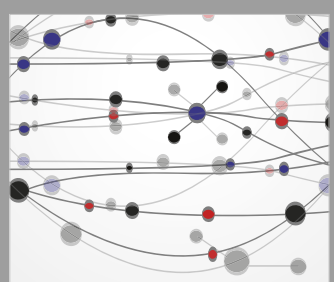

The Scientific World Journal
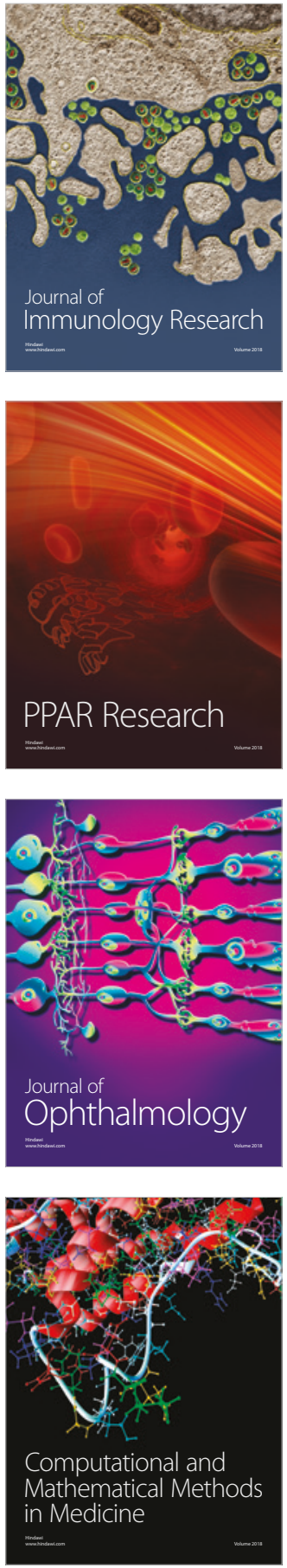

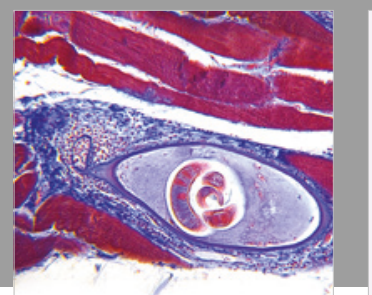

Gastroenterology Research and Practice

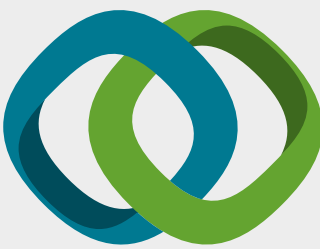

\section{Hindawi}

Submit your manuscripts at

www.hindawi.com
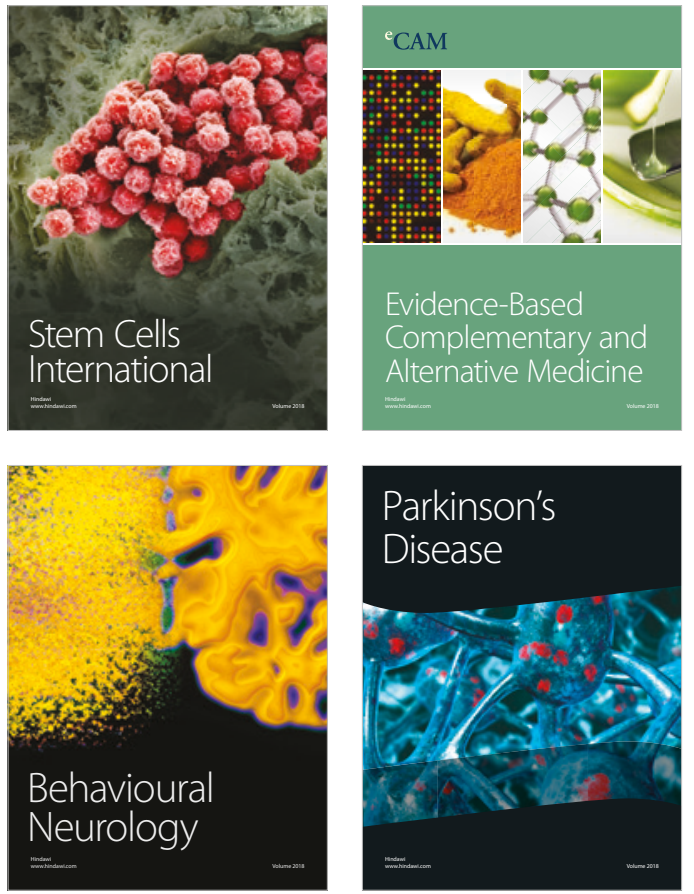

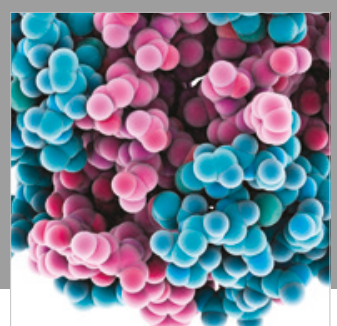

ournal of

Diabetes Research

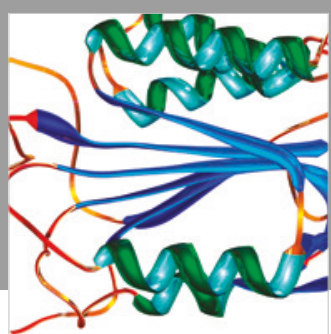

Disease Markers
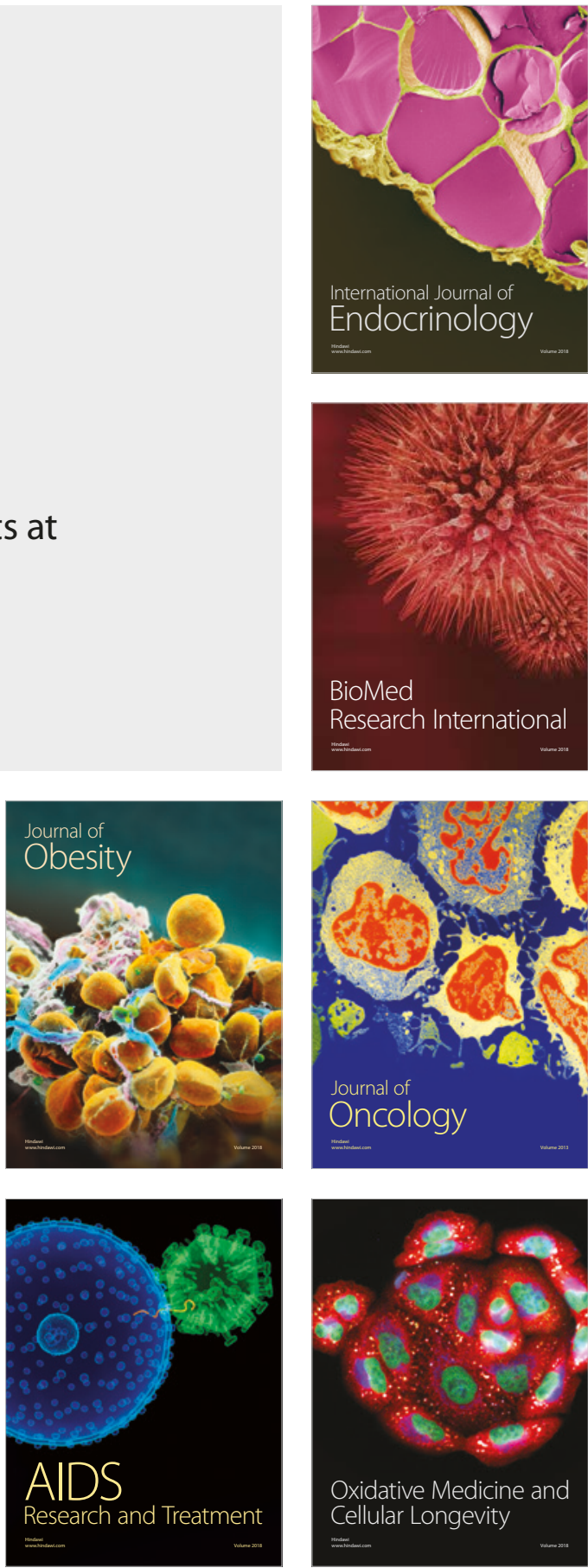